\title{
Locura y crimen en el discurso médico-jurídico. Argentina, Territorio Nacional de la Pampa, ca. 1900
}

\author{
María Silvia Di Liscia y María José Billorou \\ Universidad Nacional de la Pampa
}

\begin{abstract}
El objetivo de este artículo es el análisis de una patología mental, la histeria, en relación con la criminalidad de género y la elaboración ética de referentes positivo-negativos, observando la forma en la cual se resuelven a nivel discursivo y en las prácticas sociales concretas. Remite en primer lugar a un acercamiento particular al problema jurídico que conecta crimen y locura en un territorio del interior argentino. De esta manera, la caracterización de una enfermedad mental en un ámbito específico, permite observar la aplicación en niveles secundarios de la ideología positivista finisecular y su adaptación a la resolución de problemas concretos. Finalmente, posibilita indagar no sólo la actuación médica y judicial sino también de las elaboraciones discursivas de los profesionales sobre las patologías mentales femeninas y masculinas, en las cuales está imbricada una conceptualización de la "cuestión social" en el interior argentino, que incluye a las relaciones de género.
\end{abstract}

PALABRAS Clave: locura, género, Argentina, discurso médico-jurídico

The aim of this article is to analyze a mental pathology, that of hysteria in relation to gender criminality and the ethic making of positive-negative referents, noting the ways in which they turn into discourse and into specific social practices. In the first place, affords the study a special approach towards the judicial question that connects madness and crime in an interior part of Argentina. The characterisation of a mental illness in particular allows us to comment on the application of fin-de-siecle positivist ideology in secondary levels and its adaptation to the solution of certain problems. Finally, it helps us examine not only medical and judicial behaviour but also the construction of professional' discourse about feminine and masculine mental pathologies, within which an idea of the social problem of Argentina's interior is embedded, one that includes gender relations.

KEYwORDS: madness, gender, Argentina, medical- legal discourse

En 1901, el español José Astibia, llamado a declarar ante la comisaría de General Acha por la desaparición de un jornalero y sin mediar palabra ante el requerimiento del comisario Ibarra, atacó a su acusador con un

1 Este artículo es un aporte al Proyecto de Investigación "Género y discurso médico-psiquiátrico"(aprobado en FCH, UNLPam, La Pampa, Argentina, 2001). Agradecemos a Jorge Etchenique, del Archivo Histórico Provincial, a Selva Olmos y Andrea Lluch de la Facultad de Ciencias Humanas, a Hilda Leda del Registro Civil de Santa Rosa y al personal del Archivo Histórico Judicial de Santa Rosa por la información suministrada. Abreviaturas utilizadas: AHP: Archivo Histórico Provincial "Fernándo Aráoz". RMQ: Revista Médico-Quirúrgica. AHJ: Archivo Histórico Judicial. ACC: Archivos de Criminología. y Ciencias Afines. ACOP: Archivo de la Colonia Open Door. RC: Registro Civil. 
cuchillo y lo apuñaló. En el juicio penal y civil que posteriormente se llevó a cabo, el homicida fue considerado "incapaz", privado de sus derechos civiles y declarado inimputable de ese crimen por demencia. La enfermedad mental que lo aquejaba en el momento del ataque fue calificada por el médico que lo examinó como "manía aguda", exacerbada por un "delirio nervioso".

Cuatro años después y también en General Acha, el homicidio de Fermina Díaz, viuda de Giménez, perpetrado contra su amante Gregorio González (a) Pata de Palo, fue considerado por el peritaje médico de la defensa como un crimen inimputable, ya que la mujer sufría de "manía histérica". Sin embargo, el juez Baltasar Beltrán, quien también había actuado en el juicio de Astibia, desestimó el examen médico, dictando para Fermina Díaz una sentencia de doce años de presidio.

El estudio de ambos casos remite en primer lugar a un acercamiento particular al problema jurídico que conecta crimen y locura en un territorio del interior argentino. De esta manera, la caracterización de una enfermedad mental en un ámbito específico, fuera de los círculos médicos donde se discutió inicialmente, permite observar la aplicación en niveles secundarios de la ideología positivista finisecular y su adaptación a la resolución de problemas concretos. En segundo lugar, los dos casos no son sólo ejemplificadores de la actuación médica y judicial sino también de las elaboraciones discursivas de los profesionales sobre las patologías mentales femeninas y masculinas, en las cuales está imbricada una conceptualización de la "cuestión social" en el interior argentino, que incluye a las relaciones de género. ${ }^{2}$

La construcción del Estado en un ámbito específico - el Territorio Nacional de la Pampa—, implicó además de la organización institucional y administrativa la imposición de determinados valores propios de la sociedad capitalista. Entre éstos, pueden citarse el respeto a la propiedad privada, el recato, el trabajo, la obediencia, la honestidad, la verdad y el remordimiento. ${ }^{3}$ Tal como se ha señalado, la educación ética incluyó a Aires 2000

2 Suriano, Juan, comp.: La cuestión social en Argentina, 1870-1943, La Colmena, Buenos

3 En relación con el derecho a la propiedad, Argeri, María Elba: "Mecanismos políticos y expropiación de las sociedades indígenas pampeano patagonicas, Río Negro (1880-1930)", Quinto Sol, n. ${ }^{\circ}$ 5, 2001, págs. 13-42, señala que en la Patagonia de finales del siglo XIX y principios del XX, se trató de un elemento fundamentalmente correctivo y represivo para ejercer el control sobre la población indígena vencida, para quienes el "robo" de ganado no era un delito, sino una forma de vida. Igual situación puede observarse en el énfasis puesto en la monogamia y en la honestidad, valores centrales para la conformación de un ideal familiar nacional y en abierta contradicción con el modelo de organización comunitario mapuche. Por otra parte, el trabajo ya clásico de Hugo Vezzetti: La locura en la 
instituciones muy diversas, como las pedagógicas, represivas y jurídicas, ${ }^{4}$ ámbitos que el discurso médico sembró de metáforas higiénicas sobre el "contagio" y el consecuente derecho a la defensa social de la degeneración étnica y la disolución nacional.

La criminología positivista, que durante un largo período temporal fue la base teórica de análisis bajo la cual se desarrolló el sistema jurídico argentino, consideraba a las transgresión femenina como consecuencia de una naturaleza psicobiológica, la cual era fundamentalmente distinta a la masculina. ${ }^{5}$ Por lo tanto, esto daba lugar a un "doble sistema punitivo", en el cual varones y mujeres eran caracterizados de acuerdo a estereotipos de género, aunque el mismo sistema estuviera en contra de discursos discriminatorios. ${ }^{6}$ Nuestro estudio implica asumir los nuevos paradigmas de relación entre derecho y sociedad, definidos por la criminología crítica y el enfoque de la reacción social. El proceso de criminalización y la construcción social de la criminalidad dependen de las mismas variables con las cuales se produce el poder en la sociedad, las posiciones de ventajasdesventajas y la desigual repartición de riesgos. Determinados elementos simbólicos, como los roles femenino-masculino así como la posición social, en el plano material, constituyen variables independientes que condicionan la selectividad del sistema jurídico, dado que éste está inmerso en la realidad social.

En el análisis de delitos cometidos por mujeres, de acuerdo a la criminología crítica, se debe considerar la doble mirada del sistema, que estima aún hoy a una supuesta naturaleza femenina débil, anormal respecto al varón y en consecuencia, se le asegura "impunidad" y trato más favorable que a su contraparte masculino. Por otra parte, cuando las mujeres se alejan de los roles femeninos tradicionales y se comportan como hombres, las mujeres infringen sobre todo los roles de género y son sancionadas por esta

Argentina, Folios, Buenos Aires, 1985, señala que la construcción de la locura a partir de la psiquiatría implicó la afirmación ética de valores burgueses como el equilibrio, la decencia y la temperancia, en oposición a la exageración de todo tipo, mientras que Ricardo Salvatore: "Criminología positivista, reforma de prisiones y la cuestión social/obrera en Argentina”, en: Suriano, Cuestión social..., págs. 125-158, reafirma la idea de Vezzetti y agrega el énfasis puesto en la obediencia y en el trabajo, como se deduce de la importancia otorgada a los talleres en las penitenciarías y cárceles para la regeneración de los delincuentes sobre todo en Buenos Aires.

4 Salvatore, Ricardo: "Sobre el surgimiento del Estado Médico legal en la Argentina, (18901940)”, Estudios Sociales, n. ${ }^{\circ}$ 20, año XI, 2001, págs. 81-114.

5 Larrandat, Lucila: "Control social, derecho penal y género", en Birgin, H., comp.: Las trampas del poder punitivo. El género del derecho penal, Biblos, Buenos Aires,2000, págs. 86-87.

6 Zaffaroni, Raúl: "El discurso feminista y el poder punitivo", en Birgin, H., comp.: Trampas... El género del derecho penal, Biblos, Buenos Aires, 2000, págs. 19-37. 
conducta desviante, cuestión que afirma también la teoría feminista sociojurídica. $^{7}$

El objetivo de este artículo es el análisis de una patología mental, la histeria, en relación con la criminalidad de género y la elaboración ética de referentes positivo-negativos, observando la forma en la cual se resuelven a nivel discursivo y en las prácticas sociales concretas. En principio, se plantea la dificultad de definición nosológica de la entidad "histeria" y las diferentes posturas en relación a la responsabilidad penal; en segundo lugar, se comparan dos casos particulares, los cuales pueden visualizarse como modelos de aplicación dinámica y que están entrelazados —en oposición o concordancia - con discursos médicos y jurídicos. Esta cuestión ha sido estudiada en Argentina, ${ }^{8}$ pero no ha recibido ninguna atención en el caso particular del Territorio Nacional de la Pampa, por lo cual presenta un desafío especial para la investigación histórica.

\section{De enfermedad del útero a dolencia psíquica}

El trayecto histórico de la histeria es ejemplificador de la elaboración médica diferencial y diferenciadora del cuerpo femenino. ${ }^{9}$ La tradición clásica griega acuñó la denominación histeria en relación directa con el útero. En el siglo XIX, una reconceptualización de la naciente psiquiatría consideró que no se trataba de una dolencia causada por el aparato reproductor sino que tenía una localización cerebral. Con la Escuela de París, a partir de las investigaciones de Charcot en la Salpetrière, la histeria adquirió un rango médico singular, al vincularse directamente a la sugestión. ${ }^{10}$ Las crí-

7 Smart, Carol: "La teoría feminista y el discurso jurídico", en Birgin, comp.: El derecho en el género y el género en el derecho, Biblos, Buenos Aires, 2000, págs. 31-71 y Baratta, Alejandro: "El paradigma del género. De la cuestión criminal hacia la cuestión humana", en Ruiz, A.: Identidad femenina y discurso jurídico, Biblos, Buenos Aires, 2000, págs. 99-133.

8 Una excepción la constituyen Hugo Vezzetti: Historia de la locura..., Salessi, Jorge, Médicos, maleantes y maricas. Higiene, criminología y homosexualidad en la construcción de la nación argentina (Buenos Aires, 1817-1914), Beatriz Viterbo, Rosario, 1995, Ruibal Beatriz, "Medicina legal y derecho penal a fines del siglo XIX", en: M. Z. Lobato, ed. Política, médicos y enfermedades. Lecturas de historia de la salud en la Argentina, Biblos, Buenos Aires, 1996, págs. 193-207.y más recientemente Ricardo Salvatore: "Sobre el surgimiento"... y Scarzanella, Eugenia: $N i$ gringos $n i$ indios. Inmigración, criminalidad y racismo en Argentina, 1890-1940, Universidad de Quilmes, Quilmes, 2002.

9 Gay, Peter: La experiencia burguesa. De Victoria a Freud. T. I: La educación de los sentidos. FCE, México, 1992, págs. 313-316, Laqueur, Thomas: La construcción del sexo. Cuerpo y género desde los griegos hasta Freud. Cátedra, Valencia, 1994, págs. 300-308.

10 Charcot, J.M.: Leçons sur les maladies du système nerveux faites à la Salpetrière, Adrien Delahaye et E. Lécrosnier Ed., Paris, 1880, T. I y II y Janet, Pierre, L'état mental des hystériques, Félix Aleam, Paris, 1911. 
ticas de la Escuela de Nancy a las exageraciones respecto de la relación histeria-hipnotismo llevaron a considerar esta enfermedad como un desequilibrio funcional, propio de las mujeres pero sin excluir totalmente a los varones. ${ }^{11}$ Posteriormente, a partir del modelo psicológico freudiano, pasó a estudiarse como un desorden en los mecanismos de representación. ${ }^{12}$

En Argentina, la histeria ejerció una atracción fascinante en los profesionales, en la medida que su caracterización sintomática le daba status académico y permitía interpretar científicamente los desarreglos nerviosos y la inexplicable somatización de las pacientes. Ya en 1870, la Revista Médico-Quirúrgica (RMQ) acordaba con las tesis occidentales en boga respecto a la ubicación de la histeria en los ovarios, considerando que la compresión de los mismos era una terapia eficaz en casos de mujeres jóvenes con perversión de la vitalidad y alteraciones sensoriales que llegaban hasta la anestesia corporal, los espasmos y convulsiones. ${ }^{13}$ Se trataba de una patología que, en determinados casos, implicaba la internación. ${ }^{14}$

11 Ver Bernheim, H.: Hypnotisme, suggestion psycothérapie. Etudes nouvelles, Octave Doin Editeur, Paris, 1891.En el marco del presente trabajo y por su complejidad no es posible describir en su totalidad "la historia de la histeria".Una síntesis crítica en Bernheimer Charles, "Introduction", en: Bernheimer, C., and Kahone, C.: In Dor'as Case. Freud. Hysteria. Feminism, Columbia University Press, New York, 1990, págs. 1-7, Micale, Mark: "Hysteria and its Historiography: the future perspectives", en: History of Psychiatry, 1, 1990, págs. 33-124. y Shorter, Edward: "Mania, Hysteria and Gender in Lower Austria, 1891-1905”, en History of Psychiatry, 1, 1990, págs. 3-31.

12 Freud inició su estudio de las neurosis, que llevó posteriormente a la elaboración del psicoanálisis, a partir de casos de histerismo femenino y de una revisión crítica de las teorías neurológicas de Charcot. Una síntesis de las críticas a las consideraciones de Freud en el caso de histeria más famoso (el caso Dora) puede consultarse en Porter, Roy: Historia social de la locura, Crítica, Barcelona, 1989, págs. 159-167, Berheimer y Kahone: In Dor'as Case. De acuerdo a Alexander, Franz y Shapiro, Louis: "Neurosis, transtornos de conducta y perversiones", en F. Alexander, Psiquiatría dinámica, Paidós, Buenos Aires, 1962, págs. 115-122, las neurosis son infructuosos e inadecuados intentos de restablecer el equilibrio emocional perturbado por la presencia de impulsos subjetivos insatisfechos o escasamente satisfechos. En la histeria particularmente, la percepción interna está sobre todo perturbada por la represión. Entre los "Tipos de estado neuróticos", se menciona la neurosis de angustia, donde no hay mecanismo de represión, las fobias — acrofobia, agarobia, etc - y la histeria por conversión, en la cual los pacientes alivian la tensión emocional mediante cuadros somáticos. Estas formas de histeria por conversión implican un alto simbolismo corporal y están determinadas por experiencias traumáticas del individuo.

13 Revista Médico Quirúrgica, 1870, pág. 213. Se trata de la primera publicación médica argentina, editada de 1864 a 1888. En relación con la terapia utilizada, coincido con Valeria Pita en que no hay datos para afirmar la aplicación en el país de la operación de Battlay o Hegar (ovariotomías laterales con extirpación quirúrgica de ovarios sanos). Valeria Pita: "Damas, locas y médicos. La locura expropiada", en Gil Lozano, Fernanda et al.: Historia de las Mujeres en la Argentina. Colonia y Siglo XIX, Taurus, Buenos Aires, 2000, págs. 273-293.

14 Ver Cuadro Estadístico del Movimiento de Enfermas del Hospital General de Mujeres (dependiente de la Sociedad de Beneficencia) durante el mes de julio, en $R M Q, 1873$, p. 158. En 1874, en la estadística del Hospicio de Mujeres alienadas en la Convalecencia, el diagnóstico de "Histeromanía" incluyó a 19 pacientes de las 129 entradas, $R M Q, 1874$, p. 378-379. Osvaldo Eguía, en 
En 1879, se publica en Buenos Aires la primera obra de José María Ramos Mejía, Las neurosis de los hombres célebres de la República Argentina, prologada por Vicente Fidel López, que por sus características tuvo un gran impacto en el ambiente intelectual porteño. En el esquema general del autor, estaba vigente la oposición sarmientina de civilizaciónbarbarie, tal como aparece en el diagnóstico de las supuestas neurosis de los caudillos, lo que asimismo demuestra una visión organicista de la sociedad. Para Ramos Mejía, las "epidemias de histeria" que asolaron las provincias argentinas en los fatídicos años ' 20 , se debieron a las perturbaciones generales del orden político y social, que hicieron mella en el carácter femenino, sensible por naturaleza, y en la débil organización psicológica de las mujeres. ${ }^{15}$

La histeria asumió una importancia singular a principios del siglo $\mathrm{XX}$, tal como se demuestra en los estudios realizados al respecto por diferentes especialistas, muchos de los cuales fueron publicados en los Archivos, revista científica argentina de gran prestigio. ${ }^{16}$ José Ingenieros, discípulo de Ramos Mejía y uno de los más importantes alienistas argentinos de inicios del siglo XX, continuó con esta línea teórica en las diversas obras escritas relacionadas con la locura en Argentina. En Locura y Sugestión, escrita bajo el nombre original de Accidentes histéricos y sugestiones terapéuticas, ponía a consideración la experimentación llevada a cabo en el Servicio de Enfermedades Nerviosas del Hospital San Roque, dependiente de la

las observaciones generales, afirmaba que el aislamiento a que están sometidas las internas procede a su curación, recomendando calurosamente este método. En 1880, los higienistas Emilio Coni y Lucio Meléndez presentaron una estadística en la que compilaban desde 1864 hasta esa fecha los adelantos en la atención de los alienados, puntualizando las causas de la locura en Buenos Aires específicamente (instrucción, inmigración, celibato, entre otras), información ya publicada en forma parcial en la $R M Q$. En el artículo, destinado en parte a probar la falta de instituciones adecuadas en el país para la atención de alienados, no figuran las patologías diferenciadas en el Hospicio de las Mercedes o en el Hospital de Alienadas.

15 Ramos Mejía, José María: Las neurosis de los hombres célebres de la República Argentina, Talleres Gráficos Rosso, Buenos Aires, 1932 (1879), págs. 133-136.

16 El nombre completo de la publicación es Archivos de Criminología. y Ciencias Afines. En su primera etapa, de 1901 a 1912, fue dirigida por José Ingenieros. Posteriormente a esa fecha se denominó Revista de Criminología, Psiquiatría y Medicina legal y fue dirigida por Osvaldo Loudet. En esa primera etapa aparecen 6 artículos vinculados con la histeria, tanto de experiencias realizadas en instituciones argentinas como en México y Uruguay. Ver al respecto Durquet, Joaquín: "Manía ambulatoria y epiléptica y monoplegia histérica", ACC 1906, año V, p. 333-343, y "Paraplegia histérica. Curación por sugestión", ACC 1905, año IV, págs. 306-317,; Bello, Nicolás: "Fiebre histérica con hemianopsia pasajera", $A C C, 1909$, año VIII, págs. 66-74, Abogado, E. L.: "Rehabilitación de alienados. Un caso de histeria delirante curado", ACC 1907, año VI, págs. 223-236, Etchepare, Bernardo: "Histeria y síntoma de Ganser", ACC,1909, año VIII, págs. 295-299, Ingenieros, José: "La risa histérica”, ACC, 1904, año IV, págs. 349-365. No existe en ellos, al menos directamente, la relación histeria-crimen. 
Facultad de Medicina. Como Jefe del Servicio, Ingenieros observó a pacientes a los que diagnosticó histeria en sus distintas manifestaciones, entre los cuales había una mayoría de mujeres. ${ }^{17}$

Para Ingenieros, defensor pero también crítico de las doctrinas de Charcot en Argentina, la histeria era una neurosis permanente que se manifestaba en las pacientes a partir de estigmas, que éstas no sospechan que tienen y que el médico busca y descubre. Los trastornos de la sensibilidad llevaban entonces a la formación de "zonas histerógenas" a nivel cutáneo, a trastornos motores y psíquicos. Por otra parte, en los accidentes histéricos, las pacientes manifestaban episodios sin reglas fijas, de grandes contorsiones y movimientos, con vértigos, convulsiones y ataques. ${ }^{18}$

En la terapia para curar la histeria, que como nosología era compleja por su múltiple manifestación clínica, se sugería en principio el uso del bromuro de potasio, lo cual parece haberse generalizado al menos en los/las pacientes que recibió Ingenieros en el Servicio, pero al que él en particular consideraba insuficiente y errado, ${ }^{19}$ recomendando la hipnosis como método terapéutico ideal. La sugestión con fines científicos, que para Charcot implicaba directamente a la histeria, significaba para Ingenieros un importante hallazgo, toda vez que el médico podía a partir de ella instruir al enfermo y sugestionarlo para que gobernara su cuerpo y su mente. Nouzeille ${ }^{20}$ ha llamado la atención sobre la teatralización en las cátedras de estos famosos profesionales de la medicina de las prácticas hipnóticas y sobre la manipulación del cuerpo de los pacientes, sobre todo mujeres, en

17 Los casos clínicos que aparecen relatados son 15 , de los cuales hay 11 mujeres y 4 varones. La enumeración es la siguiente, considerando las descripciones clínicas tal como aparecen en la obra: 1. Histeria epileptiforme (mujer, 18 años, soltera), 2. Hemiplejía histérica (varón, 24 años, casado, católico, idóneo de farmacia), 3. Astacia o abasia (mujer, 14 años, soltera, hija de agriculturores, argentina), 4. Risa histérica (mujer, 17 años, argentina, soltera, católica), 5. Hipo histérico (mujer, 15 años, soltera, raza judía), 6. Mutismo histérico (mujer, 22 años, argentina, casada), 7. Disnea histérica (mujer, 25 años, criolla, soltera), 8. Sudor de sangre (mujer, 27 años, soltera), 9. Fiebre histérica (varón, 30 años, cubano, casado), 10. Seno histérico (mujer, 22 años, casada, argentina), 11. Edema histérico (mujer, 14 años, soltera), 11. Abulia histérica y dipsomanía (mujer, 27 años, soltera), 12. Psicastenia o neurosis obsesiva (3 casos: varón, joven, argentino, estudiante, varón, 16 años, soltero, estudiante y mujer, joven soltera). Varios de estos casos fueron también publicados en los Archivos, Ingenieros, José: "La risa...".

18 Ingenieros, José: Histeria y sugestión. Estudios de psicología clínica, en Ingenieros, José: Obras Completas, T. II, Mar Océana, Buenos Aires, 1962 (1910), pág. 21.

19 El bromuro fue considerado un "chaleco químico" que no permitía la curación sino el entorpecimiento de la actividad funcional, al calmar la agitación circunstancial (Ingenieros, José, Histeria..., pág. 43.

20 Nouzeilles, Gabriela: "Políticas médicas de la histeria. Mujeres, salud y representación en el Buenos Aires de fin de siglo", Mora. Revista del Instituto Interdisciplinario de Estudios de Género, n. ${ }^{\circ}$ 5, oct-1999, Buenos Aires, págs. 97-110. 
las cuales se generaban mecánicamente zonas histerógenas — generalmente insensibles- y zonas frenadoras, las que bastaba con presionar para eliminar el ataque histérico.

\section{La criminalización de la histeria}

Como se ha señalado, este análisis significa abarcar de forma más profunda la relación locura-crimen en el interior argentino, en un momento clave de la formación del Estado territorial. La Pampa, ubicada en el centro del país, fue Territorio Nacional desde su formación en 1884 hasta 1951, cuando se denominó Provincia Eva Perón (en la actualidad, Provincia de La Pampa). La etapa de poblamiento se inicia luego de la Campaña al Desierto de 1879, que eliminó del control territorial a los pueblos nativos, con aporte demográfico de las provincias vecinas e inmigrantes extranjeros. ${ }^{21}$

El Territorio en particular se incorporó como espacio productivo a partir de una economía pastoril dominante a finales del siglo XIX, posteriormente desplazada a las zonas del Este pampeano por una cerearicultura en expansión, en relación con la exportación y la apertura del mercado externo. Las primeras poblaciones - Victorica y General Acha- se ubicaron en principio en el Oeste pampeano, pero luego y en coincidencia con la modificación del proceso productivo, se desarrollaron las ciudades del Este, entre las cuales destacó General Pico y Santa Rosa, ésta última fundada en 1892 y capital del Territorio desde 1904.22

21 Entre 1887 y 1895 se duplicó el número de pobladores del Territorio debido a una sorprendente tasa de crecimiento anual del 10,1\%, de 1895 a 1905, la tasa fue de 7,18\% anual. Estos índices eran reflejo del aumento de la demanda de población, producto a su vez de la demanda de bienes y servicios de un espacio económico en expansión, proceso que en gran medida se apoyaba en la dinámica interna de una economía en crecimiento. Esta situación aceleró a su vez el proceso migratorio. De acuerdo al Censo Territorial de 1912, los migrantes extranjeros representaban el $40 \%$ aproximadamente de la población en su conjunto (Lluch, Andrea, Informe de Avance, Proyecto de Investigación: La construcción del género femenino en las reformas sanitarias del peronismo (1946-1955), FCH, UNLPam, Santa Rosa, 1998 (mimeo).

22 Ver Maluendres, Sergio: "El proceso de conformación de la frontera productiva en La Pampa”, en Lluch, Andrea y Lassalle, Ana M., Arando en el desierto. Itinerario fotográfico de la colonización francesa de Telén. Pampa Central, 1900-1914, FCH, UNLPam, Santa Rosa, 2001, págs. 27-28. En 1895, Victorica y General Acha, las dos localidades del Oeste que eran además las más importantes del Territorio, tenían 1323 y 883 habitantes. En 1914, las ciudades del Este superaron en población a las del Oeste: General Pico tenía en ese momento 6404 habitantes, Santa Rosa 5487 y General Acha, 3266. Ander Egg, Ezequiel: La Pampa. Esbozo preliminar para un estudio de su estructura socio-económico. Vol. I: Demografía, Asesoría Técnica, Santa Rosa, 1958, información tomada de los Censos Nacionales de 1895 y 1914. 
La organización política merece algunas aclaraciones. La categoría de "territorio nacional" implicó que el gobierno estaba a cargo de una autoridad elegida por el Poder Ejecutivo Nacional, por lo cual, las elecciones se limitaron al ámbito municipal. ${ }^{23}$ Sin embargo, a causa de las endémicas dificultades presupuestarias, los gobernadores del Territorio no tuvieron una burocracia acorde a la inmensa tarea a desarrollar. La administración de la justicia y el orden policial se presentaron como dos importantes cuestiones a resolver, mientras que el desarrollo de instituciones sanitarias no obtuvo igual interés en la agenda estatal ${ }^{24}$ Esta preocupación por la seguridad se relaciona con el bandolerismo y el cuatrerismo y se refleja en un aumento de la tasa de homicidios que en comparación con otras regiones argentinas resultaba alarmante..$^{25}$

En el Territorio pampeano, muy tempranamente, se llamó la atención sobre la necesidad de contar con una cárcel. A principios de siglo, existían dos, una en General Acha y otra en Santa Rosa, ésta última construida originariamente en los terrenos reservados para un Hospital. ${ }^{26}$ En relación con los enfermos mentales resulta llamativo observar la carencia de institucio-

23 De acuerdo a Favaro, Orietta y Arias Bucciarelli, Mario: "El lento y contradictorio proceso de inclusión de los habitantes de los territorios nacionales a la ciudadanía política: un clivaje en los años '30”, Entrepasados, Revista de Historia, año V, n. ${ }^{\circ} 9,1995$, págs. 7-26, los territorios nacionales surgieron como entes geográfico-administrativos de carácter temporario y se formaron con tierras que se encontraban dentro de las zonas juridisccionales atribuidas a las provincias y que, luego de la campaña militar contra la población nativa, se incorporaron a la nación. Su organización y gobierno quedó definida a partir de la Ley 1532 de 1884, que apuntaba a fusionar los intereses locales, evitar la división y subordinar el interés regional al nacional. El gobierno central consideraba que los territorios debían transitar desde esta condición subordinada al status provincial y lograr así una efectiva federalización. Este proceso fue muy lento, e interrumpido por razones políticas y económicas, que no es posible por su complejidad ahondar en este trabajo. De acuerdo a la legislación nacional, los territorios que pasaran los 60.000 habitantes podían ser declarados provincias, pero a pesar que ya en 1914 superaba esa cantidad, la Pampa en particular no fue provincia hasta el inicio de los años ' 50 .

24 Dicha preferencia tiene relación con las características particulares del Territorio pampeano, ya que existía en las autoridades un optimismo (quizás poco reflejado en la realidad) respecto a la salud general en la población. La única prueba al respecto sería en principio la relativamente escasa incidencia de las epidemias, lo cual hizo innecesario, de acuerdo a la mentalidad de la época, la funcionalización de un sistema sanitario más extenso y complejo. De todas maneras, se trata de una hipótesis que excede este trabajo y que será explorada en el futuro.

25 Entre 1910-1914, la tasa de homicidios era en Buenos Aires de 0, 89 por cada diez mil habitantes mientras que en La Pampa, trepaba a 3,90. La situación fue común a otros territorios; en Neuquén por ejemplo era aún mayor, de 5,38 cada diez mil. Bohoslasky, Ernesto: "Rueda de reconocimiento. Delincuentes y delito en Neuquén, 1900-1930", en Gentili, M. B., et al, Historias de sangre, locura y amor, Neuquén 1900-1950, Publifadecs, General Roca, 2000, pág.: 25.

26 Ver como ejemplo la Memoria administrativa de la Gobernación, del Gobernador Diego González: AHP, Diario La Capital, 29-03-1905, 12-04-1905 y 15-04-1905. 
nes específicas, debido a que el Estado territorial tenía una capacidad administrativa muy limitada, los recursos del Estado nacional eran escasos y por otra parte, la cantidad de personas en estas condiciones no sugerían una necesidad urgente, ${ }^{27}$ apareciendo más eficaz la derivación. Durante el período 1898-1930, los insanos que no podían quedarse con sus familiares, ya fuera por el carácter violento o por la imposibilidad de contención familiar, fueron derivados a los Hospicios de la Provincia de Buenos Aires, de la Capital Federal o de la Provincia de Córdoba, en el caso de que fuesen indigentes, o bien a los Asilos privados de la Capital. ${ }^{28}$

La práctica de concentrar enfermos en las provincias del Litoral y en Capital fue común a la mayoría las provincias y territorios argentinos. La aglomeración y el apiñamiento fueron normales desde finales del siglo XIX, pero se transformaron en una nueva preocupación en las primeras décadas del XX, cuando el pesimismo terapéutico llevó a los especialistas a reflexionar sobre la imposibilidad terapéutica en tales condiciones. $^{29}$

En relación con la Justicia, se debe señalar que de acuerdo a la legislación vigente, existía en el Territorio un juzgado letrado que tenía a su cargo el fuero civil, penal y comercial y que ejercía asimismo como tribunal de apelación de los doce juzgados de paz existentes en los quince departamentos pampeanos. Uno de los primeros jueces letrados, Baltasar Beltrán, puede ser considerado representante de una concepción naturalis-

27 El registro de insanos "oficiales", es decir, de aquellas personas a quienes se les realiza el juicio civil fue entre 1898-1910 de 11 casos. Podemos suponer una cantidad mayor de enfermos mentales que no llegaron al Tribunal y que vivían con sus familias, que como señala Ingenieros (1920) era una práctica común, pero carecemos de información al respecto

28 De acuerdo a la primera evaluación de los expedientes sobre Insania, el circuito era el siguiente: los supuestos enajenados eran derivados de las distintas localidades pampeanas a Santa Rosa y allí examinados por los médicos en la Asistencia Pública, institución que se fundó en 1911 (antes de esta fecha, por los médicos de Tribunales). Posteriormente, si se hacía lugar al juicio de Insania y el enfermo no tenía parientes para el traslado, el Estado territorial corría con los gastos de pasaje en ferrocarril, para llevarlo generalmente al Hospicio de las Mercedes. Posteriormente, algunos pacientes eran trasladados a la Colonia Open Door en Luján (Buenos Aires) y la Colonia Oliva (Córdoba). Un listado sobre los manicomios existentes en esa época en Ingenieros, José: La locura en la Argentina, Cooperativa Editorial Limitada, Buenos Aires, 1920 y Meyer Arana, Alberto: La caridad en Buenos Aires, T. I y II, Sopena, Barcelona, 1911. Todavía en 1933, el Director de la Asistencia Pública de Santa Rosa, Dr. Mario Cabello, solicitaba la creación en el Territorio de un frenopático, dada la demanda creciente de ese servicio, AHP, Informe para la I Conferencia Nacional de Asistencia Social, Ministerio de Relaciones Exteriores y Culto, 1933, n. ${ }^{\circ}$ 791, M.

29 Ver Coni, Emilio y Meléndez, Lucio: Consideraciones sobre la estadística de la enajenación mental en la Provincia de Buenos Aires, Imprenta Pablo Coni, Buenos Aires, 1880 e Ingenieros, José: La locura en la Argentina, Cooperativa Editorial Limitada, Buenos Aires, 1920. 
ta de la sociedad pampeana, acorde por otra parte al pensamiento finisecular argentino. ${ }^{30}$

En la Memoria y Estadística escrita hacia 1905, publicada en el Diario local La Capital, el Juez consideraba que el crimen predominante en la Pampa era propio de la "pequeña delincuencia", donde se demostraba la profunda anormalidad psíquica característica de los criminales natos. $\mathrm{La}$ coincidencia de Beltrán con la doctrina de la "defensa social" esbozada por José Ingenieros a partir de la antropología física italiana no es asombrosa, habida cuenta de la enorme influencia de las teorías lombrosianas en Argentina, pero sí es interesante observar su aplicación directa en dos casos criminales.

La supuesta extensión de la histeria entre mujeres de diferentes clases sociales fue una preocupación constante para los médicos que se trasladó al ámbito judicial, en momentos en los cuales se intentaba generalizar una metodología científica en la actuación de los tribunales y jueces. Uno de los principales problemas era si la histeria podía incapacitar a una persona, haciéndole perder la conciencia y en consecuencia, ser considerada causal de irresponsabilidad jurídica.

Es necesario aclarar dos cuestiones, relacionadas entre sí: en principio, la declaración de demencia en un juicio civil implica una exclusión del contrato social, es decir, una separación del individuo de la comunidad en virtud de una enfermedad incapacitante que impide el uso de sus derechos. Por otra parte, la solicitud de declaración de demencia ante un proceso criminal implica que no existe en esa persona el reconocimiento de los deberes individuales para con la sociedad (respeto a la vida, a la propiedad, entre otros), ya que si el criminal es un insano, no puede ser consciente y responsable de haber faltado a una norma moral y a determinadas leyes.

El Código Civil sancionado a finales del siglo XIX declaraba que los dementes eran individuos de uno u otro sexo que se hallaban en "estado de manía, demencia o imbecilidad", aunque tuviesen intervalos lúcidos o una manía parcial. La declaración de demencia implicaba el inicio de un Juicio por Insania que se realizaba ante el Fuero Civil y en el cual era fundamental el peritaje de los facultativos. La legislación penal posterior señalaba la ininputabilidad de los crímenes cometidos por alteraciones morbosas de las

30 Etchenique, Jorge: Movimientos Provincialistas y Sociedad Global. Pampa Central, Primera Parte (1884-1924), Gobierno de la Pampa, Ministerio de Cultura y Educación, Santa Rosa, 2001, págs. 31-32 y Terán, Óscar: Vida intelectual en el Buenos Aires fin-de-siglo (1880-1910). Derivas de la cultura científica", Fondo de Cultura Económica, México, 2000, págs: 281-292. 
facultades mentales o por estado de inconciencia, caso en el cual merecía que el enajenado fuese recluido por orden judicial en un manicomio. Dicho transtorno mental no podía ser "transitorio" sino permanente, aunque podía aducirse a "inconsciencia" cuando se probase que efectivamente, al cometer un crimen, el individuo no había introyectado los valores morales.

Ahora bien, tal como se demuestra en los Códigos jurídicos, existió una estrecha relación entre la acción judicial y el peritaje médico. La medicina brindó a la criminología occidental naciente los elementos científicos para validar sus hallazgos y transformó de manera singular la concepción de castigo para los criminales. ${ }^{31}$ Pero diálogo no significa acuerdo total; entre jueces y médicos existieron diferencias y contrapuntos que demuestran las dificultades de la medicina positivista por integrarse de manera total, modificando no sólo las conductas de los criminales sino transformando la misma estructura penal.

Los casos que se van a tratar a continuación presentan tanto esas contradicciones como las coincidencias discursivas. Ambos tratan de homicidios fácilmente esclarecidos por la policía local, pero que por sus características dejaron una fascinación morbosa a la vez que cierta preocupación en la población de las pequeñas ciudades pampeanas, la cual se reflejó en la prensa Territorial. Uno de los crímenes accedió a un nivel mayor de impacto al ser utilizado como ejemplo del uso de una metodología científica para resolver un caso judicial en los Archivos de Criminología y el mismo Ingenieros lo utilizó como prueba en su obra Crimonología. ${ }^{32}$

\section{Falsa demencia}

En 1905, se publicó en los Archivos un artículo firmado por el juez Baltasar Beltrán en el cual se relataban los pormenores del homicidio llevado

31 El "método moral" elaborado por Pinel como terapia de la locura y su traslado a los ámbitos carcelarios implicó una renovación profunda del significado de la penalización, en la medida que ésta no tenía ya como objetivo la tortura o la mutilación corporal sino la expiación del espíritu. Una visión general de este proceso en Foucault, Michel: Vigilar y castigar, Siglo XXI, Madrid, 1986.

32 Un ejemplo al respecto son las pericias psiquiátricas realizadas a anarquistas-criminales como Cayetano Santos Godino y Alejandro Publia. Ruibal, Beatriz: "Medicina legal y derecho penal", págs. 205-207. Otros exámenes médicos publicados fueron los que se hicieron a curanderas acusadas de ejercicio ilegal de la medicina en Di Liscia, María Silvia: Saberes, terapias y prácticas indígenas, populares y científicas en Argentina (1750-1910), Colección Biblioteca de Historia de América, Madrid, Consejo Superior de Investigaciones Científicas, 2003, ver asimismo Ingenieros, José: Criminología, en Obras..., T. II, págs. 426-429. 
a cabo por Fermina Díaz en General Acha un año antes $\cdot{ }^{33}$ En la publicación, leída sobre todo por especialistas del derecho y la medicina, el elocuente título ("Homicidio y falsa locura histérica") brinda la caracterización del funcionario ante el crimen. El diario territorial La Capital da fe del hallazgo de un cuerpo en el pozo de una zona marginal, que los diligentes agentes policiales identificaron como el de Gregorio González (a) Pata de Palo. ${ }^{34}$

En el Juicio Penal seguido contra Fermina, el Agente Fiscal solicitó al Juez que se la procesara por homicidio perpretado con alevosía y ensañamiento, mientras que el defensor solicitó su absolución o disminución de culpabilidad, considerando que la mujer ejecutó el homicidio en una crisis de histerismo, ya que era neurótica. Para probar dicha dolencia, se llamó a declarar a dos peritos, los doctores José Fornes y Lucio Molas, quienes conjuntamente con el médico del tribunal, José Oliver, llegaron a la conclusión que la imputada padecía de "histeria hereditaria", sin que fuese posible precisar el grado de influencia de esa enfermedad sobre el delito cometido.

Ante el informe médico, Beltrán se lanzó a una larga disertación para analizar si la histeria podía ser o no eximente de responsabilidad penal. En el escrito demuestra un amplio dominio de las teorías dominantes en el escenario criminológico nacional. La histeria se define como una enfermedad en la cual los pacientes presentan falta de sensibilidad cutánea con zonas anestésicas y analgésicas así como alteraciones en la motilidad que impliquen inconsciencia. De acuerdo a la evaluación médica, Fermina Díaz tenía estos síntomas, junto con una incapacidad para mantener la atención, pero para Beltrán esa no era una patología sino una "debilidad mental común a las razas inferiores". ${ }^{35}$

33 Fermina era argentina y se había casado con Juan Giménez antes de 1888, posiblemente fuera del Territorio, puesto que no se encuentra la partida de matrimonio. Se trata de una unión legal, de la cual se conocen los siguientes hijos: Juan, nacido en 1890 e inscripto en 1892 en General Acha (que no se menciona en el expediente de Beltrán) y dos hijas más, una de ellas, Anita, nacida en 1888. El marido, Juan Giménez, murió en 1902 a los treinta años a causa de disfunción renal. $R C$, Acta de defunción n. ${ }^{\circ} 102$ "Fermina Díaz", General Acha, $R C$, Acta de defunción n. ${ }^{\circ} 37$, "Juan Giménez, General Acha y $R C$, Acta de Nacimiento n. ${ }^{\circ} 5$, "Juan Giménez", General Acha.

34 Bajo el sugerente título "Crónicas de sangre", el corresponsal vertía todos los detalles de un crimen que había conmovido a los pacíficos habitantes de esta localidad del Oeste pampeano. Para descubrir a la autora, los oficiales prestaron atención a las pisadas del caballo que iban y venían, y que llevaban hasta el rancho de Fermina, viuda de Giménez, quien al principio negó tener relación con el hecho pero después confesó que había dado muerte a González, con quien mantenía relaciones íntimas, por que éste había insistido en hacerlas legítimas. Ante la amenaza de su amante, que incluso ejerció la violencia contra ella y sus hijas, la mujer terminó por eliminarlo una vez que éste se acostó a dormir, golpeándolo repetidamente con un hacha. AHP, Diario La Capital, 02-04-1904. Este crimen brutal, se afirmaba dos días después, no era frecuente en el territorio sino totalmente excepcional. AHP, Diario La Capital, 04-04-1904.

35 Beltrán, Baltasar: "Homicidio y falsa locura histérica", ACC, 1905, año V, págs. 342-347. 
Pero era posible que la mujer simulara esos síntomas en razón de haber llevado una vida desarreglada. Las consideraciones morales no se hacían esperar, y el juez comentaba que existían razones lógicas para haber dado muerte a González, como las de eliminarlo para iniciar amores ilícitos con un nuevo querido, el italiano Lichardi. Para Beltrán, había un rosario de diferencias que separaban al enajenado del homicida simple que no está loco: en principio, la lógica que lleva al crimen, —en relación con las ganancias y pérdidas-, que es inexplicable en los enajenados. Por otra parte, éstos no ocultan su crimen y lo divulgan, ya que carecen de la noción de culpa. El remordimiento era esencial, puesto que demostraba el respeto por las normas morales y en consecuencia la aceptación del contrato social. ${ }^{36}$

Un artículo escrito en la misma revista tres años antes, trataba de derimir si el histerismo en la escena judicial justificaba por sí mismo la morbidez del criminal, aunque las acciones hubiesen sido realizadas en plena conciencia. Para ello, su autor, el médico F. Netri, se basó en la descripción de la histeria a partir de la psiquiatría francesa por un lado y por otro en su interpretación dentro del conjunto más amplio de las "patologías de la degeneración", y en este caso, abrevó en las fuentes de la naciente antropología criminal italiana, cuyos aportes principales fueron los de Césare Lombroso y Enrico Ferri. ${ }^{37}$

La histeria era, como ya se ha señalado, una entidad nosológica de difícil caracterización, la cual Netri en particular vinculaba directamente a las mujeres, por las razones físicas y psicológicas que no escapan al paradigma inferiorizante médico. ${ }^{38}$ Entre otras causas que predisponían la aparición de la histeria, además del género y el crimen, se encontraba la edad (pubertad), la ocupación (prostitución), y sobre todo la herencia patológica

36 Fermina había tratado de ocultar su crimen en un pozo y luego mentido ante el primer requerimiento policial. Era capaz de sentir culpa y de lamentarse por el hecho, situación que no se condice con "la ceguera moral de las alienadas histéricas", que ejecutaban los crímenes por placer. Beltrán: "Homicidio"...pág. 345.

37 Ver Peset, José L. y Peset, Mariano: Cesare Lombroso y la escuela positivista italiana, Instituto Arnau de Vilanova, Madrid, 1975, Peset, José L.: Ciencia y marginación. Sobre negros, locos y criminales, Grijalbo-Crítica, Barcelona, 1983, Pick, Daniel: Faces of Degeneration. A European Disorder, c. 1848-1918, Cambridge University Press, Cambridge, 1989, Huertas García Alejo, Rafael: Clasificar y educar. Historia natural y social de la deficiencia mental, Cuadernos Galileo de Historia de la Ciencia, CSIC, Madrid, 1998 y Huertas García Alejo, Rafael: Locura y degeneración, Cuadernos Galileo de Historia de la Ciencia, CSIC, Madrid, 1987.

38 Los huesos de la mujer son más redondos, más blandos, más delgados (con menor energía), los músculos son más sutiles, más débiles y todo su organismo está dirigido a la tarea natural de la concepción y el cuidado maternal. Por otra parte, su sensibilidad y fragilidad llevan a la conformación de un sistema nervioso impresionable, que hace que las mujeres sean toda la vida como niños grandes. Netri, F.: "El histerismo en la criminalidad”, ACC, 1902, año II, págs. 145-146, destacado nuestro. 
y la clase social. Netri consideraba que las mujeres de los sectores más altos, que se excitaban lascivamente con placeres, lujos y caprichos mundanos y las de las clases "desheredadas", gracias a la miseria y las privaciones de todo tipo, estaban condicionadas a sufrir de histeria. Sin embargo, y coherentemente con una valorización ético-social, las de las clases medias o burguesas no eran candidatas a esta neuropatía. ${ }^{39}$

Netri probaba estos argumentos a partir del criterio de las autoridades psiquiátricas, es decir, de la lectura de Legrand Du Salle, Briquet, Charcot, Moreau de Tours y Tarde, partidarios de la teoría de la degeneración y de la patologización de la histeria de acuerdo al modelo francés pre-Nancy, donde la influencia de la hipnosis se revela fundamental para la caracterización de la enfermedad. Por otra parte, consideraba que la histeria, en su grado más pronunciado, producía un severo desequilibrio de las funciones y un transtorno del carácter que se observaba en los "estigmas histéricos" pero que además introducía dudas acerca del estado de conciencia del individuo (de la "histérica", puesto que a pesar de intentar no presentar los casos como femeninos, los especialistas caían a lo largo de su discurso en esta contradicción de género).

De acuerdo a la psiquiatría francesa decimonónica, dicho autor señalaba asimismo un síntoma esencial de la histeria, que era a su vez fundamental para los casos criminales: la simulación patológica. La mentira aparecía claramente reflejada en el propio cuerpo, que aparentaba toda clase de dolencias, heridas y malestares. La somatización era analizada como un intento por "llamar la atención" a los demás, tanto al marido, a los hijos, a los padres como a los médicos. Aunque las histéricas llegaran al suicidio, aún en ese momento crucial reclamaban incesante cuidado, al dejar cartas y notas para que se publicasen. Esta actitud era otro argumento para equiparar la condición femenina a la infantil, ya que la necesidad de permanente atención y la falsedad eran propias de niños.

Por otra parte, resulta curioso que en los ejemplos de "crímenes" que brindaba Netri, extraídos de casos estudiados en Europa, las histéricas eran quienes habían sufrido sobre sí secuestros, estupros, violaciones, lesiones, robos y contusiones, las cuales eran denegadas judicialmente considerando justamente que se trataba de enfermas: las heridas y golpes resultantes de la violencia eran somatizaciones corporales, como meras simulaciones neuróticas).

39 Netri, "Histerismo...". 
En realidad, la interpretación de los actos criminales perpretados por histéricas era vaga, y llevaba para el autor a la necesidad de que cada caso fuese estudiado de manera particular, sobre todo si dichos actos se habían realizado durante un accidente histérico. En correspondencia con una marcada influencia de la escuela criminológica positivista, Netri creía que una evaluación médico-psiquiátrica llevaría a considerar en la mayoría de los crímenes la irresponsabilidad penal, puesto que el delito e histeria formaban parte, junto con otros "vicios" y patologías, de la degeneración humana. ${ }^{40}$

Aunque Beltrán podría haber conocido este artículo, ${ }^{41}$ su interpretación del caso Fermina fue completamente contraria a lo señalado por el profesional. Curiosamente, las bases teóricas de ambos, Netri y Beltrán, eran las mismas (psiquiatría francesa positivista, Legrand du Salle sobre todo y de la antropología-criminología positivista, con Lombroso, Ferri e Ingenieros), pero estos autores le sirvieron al juez para considerar la responsabilidad de Fermina y negar en consecuencia que la "histeria hereditaria" fuese causal del homicidio. Por otra parte, para Netri la argumentación central era la medicalización del delito. De forma pesimista, sostenía que abrir escuelas en la Nación no había implicado, como era la esperanza de muchos, cerrar las cárceles. El aumento de la delincuencia patológica implicaba entonces que se debían en realidad cerrar cárceles y abrir hospicios..$^{42}$ Los alienistas serían entonces los encargados de regenerar una población degenerada por los vicios y la enfermedad que produce crímenes.

Sin embargo, en la publicación de la sentencia, Beltrán consideró que la ley no podía tener en cuenta como alienados a los que eran solamente degenerados, criticando la noción de ininputabilidad tan extensa que proponía la teoría de la defensa social. Si esto fuera así, no se podría entonces aplicar el rigor de la ley a la mayoría de los delincuentes, que por serlo son también degenerados y tarados con debilidad psíquica. Para el juez, Fermina estaba dentro de esta categoría por su "raza" y clase social, pero por otra parte la remisión de la mujer a un hospicio era imposible, ya que en el examen del caso en particular y a través de la información científica, el "estado de locura" que el código penal consideraba como eximente de culpabilidad implicaba un transtorno intenso de toda la personalidad. ${ }^{43}$

40 Netri, "Histerismo...", págs 160 y 153-154.

41 Cita en particular un artículo de Ramos Mejía, Solari e Ingenieros aparecido en los Archivos en el mismo año y parece conocer la publicación en profundidad, al menos la de ese año.

42 Netri, "Histerismo...", pág: 160.

43 Beltrán, "Homicidio...”, pág. 346. 
El eje del análisis se volvía entonces al tipo de crimen cometido y a su autora. Una mujer, que asesina a su amante no por razones de honor — para proteger su virginidad, por ejemplo, o para evitar la vergüenza social - sino para iniciar relaciones ilícitas con otro amante, implicaba un cuadro de subversión de la normalidad en las relaciones de género establecidas en un territorio poblado desde hacía poco. Y si además, el varón asesinado era débil (el mismo Beltrán reconocía que se trataba de un lisiado, el "Pata de Palo"), y la mujer había ejercido el poder de decidir sobre su vida amorosa, el cuadro final que se presentaba no podía ser interpretado como locura.

El crimen no era pasional, y el juez no reconocía entonces que pudieran aplicarse las atenuantes previstas en el código ya que Fermina no había matado por su honra, para evitar un ataque sexual o irreflexivamente, para impedir que su amante la abandonara. La muerte de González se había producido por frío cálculo, cuando éste no podía defenderse y en consecuencia, la mujer había invertido los roles tradicionales de género al apropiarse de un crimen que para los juristas reclamaba una forma masculina (planificación, ocultamiento, lógica aplicada de pérdida-ganancia).

Siguiendo este razonamiento, correspondía aplicarse un castigo carcelario y de hecho, se le impusieron doce años de presidio, cumplidos en penitenciaría. En 1907, Fermina Díaz volvió a reclamar presentando su caso en la corte suprema, pero la apelación fue desestimada. En la información que el tribunal requirió a las autoridades del presidio de La Plata, donde estaba confinada desde 1905, se señaló que la mujer pasó por un estado de depresión y melancolía a uno de excitación maníaca, pero luego volvió a su estado "normal", es decir, al que tenía antes de cometer el crimen ${ }^{44}$ Claro que la evaluación de Fermina en un período en el cual todavía no formaba parte de la maquinaria judicial podría haber requerido de muchas aclaraciones, pero en el informe incluido en la sentencia de la Corte no había más precisiones. Se ratificaba la sentencia y se declaraba en consecuencia nula la apelación de exención de pena en el presidio por enajenación mental.

\section{El delirio verídico y la justificación de la alienación}

El caso de José Astibia presenta diferencias y similitudes con el de Fermina. El escenario es el mismo (General Acha) y también el período,

44 Beltrán, "Histerismo y responsabilidad penal. Sentencia dictada por el Dr. Baltasar Beltrán de Santa Rosa de Toay”, ACC, 1907, año VII, págs. 601-610. 
focalizado a principios del siglo XX, la actividad laboral que ambos desarrollaban, la franja de edad (él de 43, ella de 37) y el crimen cometido. El juez Letrado, Baltasar Beltrán, coincide en ambos expedientes y aunque los peritos médicos son diferentes, la caracterización de la enfermedad es similar ("manía aguda", en este caso y no "manía histérica").

La fuerte carga hereditaria también es significativa en los dos casos. En el extenso informe a Astibia realizado por uno de los médicos, José García, ${ }^{45}$ se hacía mención que pertenecía a una familia de españoles, trabajadores, sobrios, pero también muy callados. Esta reserva era tan cuestionable como llevar una vida viciosa, y de hecho, el médico dedicaba parte del expediente a bucear en los ancestros del homicida.

Dicha postura genealógica estaba centrada en la búsqueda de "elementos patógicos" y avalada científicamente por la teoría de la degeneración, que ya se ha mencionado aquí. A pesar de que la madre de Astibia conservaba sus facultades mentales y el padre era equilibrado y había muerto de cáncer (patología que no estaba asociada a la locura), se enfatizaba que los hermanos eran todos anormales; uno de ellos, histero-epitéptico, los otros "neurasténicos", "extravagantes" y "medio locos", aunque nunca habían perjudicado a nadie. Si se buceaba en las generaciones posteriores, también se encontrarían razones para afirmar que se trataba de una familia definitivamente neuropática, con taras hereditarias que se habían hecho carne en el susodicho Astibia. ${ }^{46}$

Por otra parte, uno y otra pueden englobarse bajo la misma condición socio-económica, en relación con la actividad laboral. Se menciona en los Archivos que Fermina es "hacendada", definición grandilocuente y que puede confundir su persona con una gran propietaria de tierras, pero La Capital proporciona una visión más acertada del ambiente que la rodea al mencionar el "rancho" donde vivía, con piso de tierra y escasos muebles ${ }^{47}$ señalando asimismo que esa vivienda era compartida por otras per-

45 Los médicos que observaron a Astibia fueron Enrique Iguña y José García. El segundo sustituyó a Iguña en su labor profesional frente al Hospital de Caridad en General Acha, por un conflicto habido entre él y las damas de la Asociación de Beneficencia, a cargo del Hospital Municipalidad de General Acha, Revista del Centenario de General Acha, 1882-1992, p. 88.

46 Legajo 8, José Astibia, Declaración de Insania, Archivo Histórico Judicial, 1901. Dicho expediente forma parte de un relevamiento general de los 166 casos de Declaración de Insania que se encuentran en el Archivo Histórico Judicial y abarcan el período 1898-1930. Astibia fue declarado alienado y en consecuencia inimputable luego del Juicio Penal realizado en 1901, por lo cual se realizó el Juicio Civil por Insania. No se encuentra el Expediente de Astibia correspondiente al Juicio Penal entre los casos que ha rescatado el Archivo Histórico Provincial, ya que puede haber formado parte de un expurgue o de la pérdida de los archivos sucedida durante el traumático traslado del Juzgado de General Acha a Santa Rosa. 
sonas de su familia. Fermina no pudo pagar un abogado y su caso fue llevado por el defensor de oficio, lo cual también evidencia una carencia económica substancial. En el caso de Juan, las precisiones respecto a su situación económica son mayores, puesto que el expediente por insania tiene como finalidad principal nombrar un curador de sus bienes - finalmente, uno de sus hermanos, Francisco-, que se componen sobre todo de ganado ovino. En el inventario, se señala que posee hacia 1901 más de 6.000 lanares y $12.210 \mathrm{~kg}$. de lana, lo cual para la época indica que José Astibia tenía recursos económicos como para sobrevivir durante el año, pero de ninguna manera se trataba de una persona acomodada. ${ }^{48}$

Ahora bien, entre las diferencias significativas que aparecen entre ambos casos se encuentra la nacionalidad, el estado civil y el sexo. Respecto a la primera cuestión, tanto los médicos como el juez tenían presente claros prejuicios respecto a los inmigrantes y a la población nativa local. La teoría de la degeneración fue útil para demostrar la debilidad y la deformación psíquica y física de las "razas" latinas, a la cual José Astibia supuestamente pertenecía por ser inmigrante español. ${ }^{49}$ Por otra parte, también los indígenas o criollos, - no sabemos en qué categoría podía estar Fermina Díaz - podían ser estigmatizados en virtud de su falta de adaptación al medio social, a partir de la aplicación acrítica de la antropología física, también en comunicación directa con las interpretaciones morelianas. Ambos, en consecuencia, eran visualizados como seres anormales, cuando la anormalidad se extendía como un manto explicativo y difuminador de las diferencias sociales y culturales.

En relación con el estado civil, se indica que Fermina era viuda desde hacía tres años, con dos hijas, una de ellas ya casada, y que José era soltero, sin que se le conocieran queridas o concubinas. La primera ya había pasado la edad crítica para concebir cuando se convirtió en homicida, pero

47 González, luego de la trifulca con Fermina para intentar imponerle su voluntad, se tendió a dormir en el suelo de tierra, tapado con un poncho y allí fue atacado por la mujer. No se encuentran menciones a los recursos de Fermina ni concretamente a su forma de vida. Posiblemente tuviera una majada chica de ovejas y uno o dos caballos, como los que utilizó para llevar el cuerpo al pozo. No se señala que tuviera un comercio o rentas de algún tipo.

48 De acuerdo a Sabato, Hilda: Capitalismo y ganadería en Buenos Aires: La fiebre del lanar, 1850-1890, Sudamericana, Buenos Aires, 1989, pág. 191, entre 1845-1884 en la Provincia de Buenos Aires, un productor inicial tenía unas 4000 ovejas, en un establecimiento de 1000 ha. Si se trataba de arrendatarios en un área marginal de producción ovina, como era el caso de Astibia en el oeste pampeano, la lana y la majada constituían un patrimonio relativo, con el que debía hacer frente a todos los gastos de su manutención.

49 Vezzetti: Locura..., Scarzanella: Ni gringos..., pág. 35. 
su vida amorosa no había acabado ni mucho menos. En el escándalo del asesinato, se define a una mujer de carácter, a quien no marcaban las conveniencias sociales y que se estimaba libre para dejar de lado un amante para asumir otros lazos amorosos, en una confusión que resultaba muy reprobable a las austeras autoridades judiciales pampeanas. El segundo, en su madurez, no tenía una pareja reconocida, que viviera con él aún sin casarse. Los dos en consecuencia eran modelos negativos de las relaciones entre varón-mujer propugnadas desde las cátedras, los púlpitos y los tribunales, donde la formación de familias bendecidas por una prole numerosa era el ideal por excelencia. ${ }^{50}$

Como se ha señalado, el resto de las variables enmarca ambos casos dentro de una problemática común, aunque a primera vista aparezcan substanciales elementos diferenciadores. La mayor distinción entre ambos casos se presenta en el sexo de los dos, la criminal y el alienado, y en las relaciones de género que inciden en la evaluación general, terminando por comprometer a una y a otro en una reclusión también diferencial.

En la actuación posterior al homicidio ya se construye esa singularidad. Tal como destaca el peritaje médico, Astibia se resistió a ser encarcelado y ejerció tal violencia contra las autoridades que hubo de ser reprimido con camisa de fuerza, duchas frías y fuertes dosis de bromuro de potasio. Luego de este período de "manía" en la cárcel local de General Acha, el alienado pasó a una etapa de melancolía, se negó a comer, a hablar y se masturbaba con frecuencia, manteniendo una actitud de apatía e indiferencia hacia todo lo que lo rodeaba, pero cuando su conducta se volvía violenta, la amenaza de la "fisioterapia", como irónicamente se menciona en el expediente refiriéndose a las duchas frías, hacía que el paciente cooperara.

Para José García, el médico que realizó la pericia, se trataba de un caso típico de locura circular, con momentos de furia que se alternaban con otros de calma. Justamente, fue durante el período de la "manía" que Astibia atacó al comisario y le dio muerte. La "lógica" de la muerte del comisario, que acusaba a Astibia de otro crimen, no estaba dentro de la visión del médico, quien consideraba que la actuación había sido típica de un insano.

50 Torrado, Susana: “Transición de la familia en la Argentina, 1870-1995”, Desarrollo Económico, vol. 39, n. ${ }^{\circ}$ 154, julio-septiembre 1999, Buenos Aires, págs. 235-260, Di Liscia, María Silvia, "Hijos sanos y legítimos. Sobre matrimonio y asistencia social en Argentina (1935-, 1948)", História, Ciencia, Saúde \& Manguinhos, Vol. 9, Suplemento, Río de Janeiro, 2002, págs. 209-232. 
En el caso del varón homicida, se hacía hincapié en su incapacidad para ocultar el crimen y en la negativa a mentir. Ante la acusación, Astibia intentó quizás evadirse (y por ello fue enchalecado), pero luego se refugió en su interior, sin dejar que los estímulos externos pudieran afectarlo. Sólo frente a las duchas frías condescendía a responder a sus guardianes, como irónicamente menciona el médico que lo revisó y observó durante días.

En cambio, la simulación está en el centro del "caso Fermina". Desde el ocultamiento del cuerpo hasta su primer interrogatorio, se negó a aceptar su responsabilidad en la muerte del amante. Pero luego aceptó la culpa y de acuerdo al juez Beltrán, lloró vencida por los remordimientos. Más adelante, de acuerdo al informe presentado para la apelación, se señalaba que su conducta era normal ya que comía, dormía y respondía a las preguntas.

Quizás la mayor diferencia de la actuación posterior a la detención entre ambos no esté en la caracterización patológica, sino en la adaptación a la privación de la libertad. La cárcel y el manicomio se transforman también en laboratorios donde se observa y se experimenta con sujetos supuestamente anormales y socialmente peligrosos, y donde consecuentemente se construye una imagen de la locura, de altísima densidad, que depende de estereotipos étnicos, de clase social y sobre todo de género.

El llanto, la desesperación sin ejercicio de violencia ante la pérdida de la libertad se perciben como conductas normales, así como aceptar el castigo y reiniciar una vida activa (aunque regulada externamente), porque en esas conductas está la clave de la regeneración del criminal. Por el contrario, la violencia infringida a sí mismo y a los demás, el aislamiento y la depresión ante el encierro son conductas anormales e indican al insano. Es la mirada del especialista la que señala las distancias, a menudo difíciles de expresar, entre dos realidades que se perciben en su dualidad más profunda. Sin embargo, cabe especular acerca de los polos y las distancias extremas para concluir sobre posibilidades y no certezas. ${ }^{51}$

De acuerdo a nuestra interpretación, es la caracterización de género en ambos homicidios la que está definiendo las conductas aceptables o inaceptables, la normalidad y anormalidad que se unen al crimen o a la locura. Un acto criminal se realiza para obtener una ganancia, ya fuese ésta monetaria, afectiva o sentimental, o para evitar un daño, real o potencial. Cuando el

51 Hay una observación meticulosa de las actividades del alienado o supuesto alienado como comer, evacuar, dormir, moverse, hablar, sobre la vida sexual y otras que se vinculan con la relación con los demás (agresión, indiferencia o cooperación, entre otras). Un ejemplo de esta observación puede encontrarse en la institución mental modelo de principios de siglo en Luján, Provincia de Buenos Aires. Ver ACOP, Boletines Annamésicos. 
crimen sale de esta categoría, pasa a formar parte de lo "inexplicable", convocando así a las fuerzas oscuras de la locura, que transcurre fuera de la lógica anterior.

En la valoración de ambos homicidios está inmersa la idea de que las mujeres son un sexo naturalmente pasivo, que su normalidad se inscribe en una vida reproductiva, donde el placer está ausente. Los varones, sean estos padres, hijos, esposos o amantes, son quienes dirigen la pareja y quienes determinan el inicio o la terminación de un romance. Por otra parte, cuando las mujeres asesinan, lo hacen sin cálculo, llevadas por una "loca pasión", que está siempre relacionada con el honor o la falta de honor. ${ }^{52}$

El caso Fermina evidentemente se sale de estos esquemas, hace agua por todos los sitios en donde se mire: ella es una mujer adulta, que aunque ya madre de hijas mayores, busca aún una vida amorosa al margen de la legalidad y de las conductas morales socialmente aceptadas. Se trata de una mujer dominante, que no depende económicamente de un varón y que decide cuándo empezar y cuándo terminar una relación aún con métodos poco ortodoxos, como eliminar a sus amantes. Para el juez Beltrán y posteriormente para los jueces de la Corte Suprema, el frío cálculo se contradice con la locura, pero además el mismo crimen está fuera de la "normalidad" delictiva femenina.

Por otra parte, Astibia fue catalogado como insano. De acuerdo al peritaje médico, de influencia lombrosiana, "Los locos tienen actividad física exagerada (...). Los delincuentes, por el contrario, tienden al ocio completo, fueron siempre ociosos, violentos, apasionados que no los locos, que son sobrios, laboriosos, solitarios, dóciles y de carácter dulce". ${ }^{53}$

52 El médico José Belbey afirmaba que las mujeres delinquían en menor medida que los varones y además, de acuerdo a la clasificación de Ferri, lo hacen porque son degeneradas (delincuentes natas, como por ejemplo, las prostitutas), porque son arrastradas por los varones a cometer un hecho ilegal o porque son llevadas por la pasión. Los delitos típicamente femeninos son el aborto, el infanticidio, el abandono de los hijos, todos éstos crímenes tenían relación con el honor y la vergüenza. Por otra parte: las mujeres que delinquen sin que lo hagan por su honor, se masculinizan: la fisonomía moral de la criminal nata demuestra una profunda tendencia a confundirse con el tipo masculino. Se trata de mujeres con débiles instintos maternales, exceso de erotismo, placer por una vida disipada, gusto por los ejercicios violentos y por los vestidos viriles. Belbey, José: La sociedad y el delito. Delincuencia colectiva de las mujeres, de los débiles mentales y otros ensayos", Claridad, Buenos Aires, 1947, págs. 77-84. Este ejemplo tardío es de un profesional que perteneció al Partido Socialista y que tenía paradójicamente opiniones progresistas en relación al aborto y a la prostitución pero que sin embargo mantiene respecto a las tipologías delictivas femeninas una caracterización positivista (Un análisis general de los delitos femeninos en Otano, Graciela E.: "La mujer y el derecho penal. Una mirada de género", en: Birgin, comp., Las trampas del poder..., págs. 111-136 y de las teorías lombrosianas acerca de los delitos femeninos en Scarzanella: Ni gringos, págs. 82-83.

53 AHJ, José Gracia, Expediente 8, 1901. 
Esta cita caracterizaba bien a Astibia, evidentemente, lo incluía en varios aspectos positivos para la moral burguesa, ya que hasta el momento de la muerte del comisario, podría ser considerado un inmigrante ejemplar, dedicado a acumular un patrimonio, aunque las taras hereditarias le habían impedido la formación de una familia y el acatamiento de las normas legales.

La muerte del comisario era analizada como producto de su patología, la cual no se denominaba manía histérica en atención a su sexo, sino manía aguda. Pero tal como Fermina, también José obtenía una "ganancia" con el homicidio, que era evitar la investigación de otro supuesto crimen (del cual, curiosamente, nada se dice en el expediente).

La enajenación mental significó para él la reclusión en un manicomio durante dos años y no en una prisión, como le sucedió a Fermina, durante doce años. ${ }^{54}$ Se podría pensar que ambas instituciones constituían un continuúm donde se sucedían similares mecanismos de vigilancia y represión, pero para diferenciarlos baste mencionar que en 1903 el Director del Hospicio de las Mercedes, envió una nota al juez Beltrán en la cual consideraba a Astibia un paciente tranquilo, que podía ser dado de alta, ya que no era peligroso ni para sí ni para los demás. Ese mismo año, fue liberado del Hospicio en Capital Federal y entregado a su hermano Francisco para su custodia, nuevamente en el territorio pampeano.

\section{Reflexiones finales}

El "caso Fermina" puede compararse con el de Carmen Guillot, una asesina que mandó eliminar a su marido en 1914, y que tuvo un gran impacto periodístico en la prensa nacional y también apareció reflejado en la Revista de Criminología. La imputación del crimen se realizó considerando que Carmen no estaba loca; en consecuencia, el delito no podía encuadrarse dentro de las atenuantes morales o justificaciones biológicas diferenciadoras habituales en la jurisprudencia paternalista. ${ }^{55}$ El caso de Carmen es posterior y revela una continuidad de los discursos jurídicos en relación con los roles de género.

54 De acuerdo a la sentencia, debió permanecer en la cárcel hasta 1917. La mujer volvió a General Acha y murió en 1938, de neumonía e insuficiencia cardíaca, cuando tenía 70 años de edad ( $R C$, Acta n. ${ }^{\circ}$ 102, Libro 5375, Folio 51 vuelta, General Acha).

55 Scarzanella, Eugenia: Ni gringos..., págs. 86-87. 
Pero si bien el análisis microhistórico permite una reducción a escala, hasta llegar a acercarnos a la vida cotidiana de un conjunto reducido de personas, lo que nos interesa señalar es que los dos casos analizados permiten ir más allá del análisis puntual, de manera tal de adentrarnos en diferentes problemas vinculados con la locura y el crimen en relación con las prácticas y discursos de alienistas y jueces, los cuales fortalecieron científicamente los mecanismos de control social. En un territorio escasamente poblado como el pampeano, cuyos habitantes estaban además distribuidos a principios de siglo en las áreas rurales, "la cuestión social" adquiere un perfil diferente al existente en otras regiones de Argentina, en la medida que no existen aquí conglomerados que justifiquen la preocupación de los expertos por los "vicios urbanos", originados por la modernización acelerada y en coincidencia con una visión conservadora de la sociedad. ${ }^{56}$

La singularidad del territorio pampeano, común por otra parte a otras regiones del interior argentino, puede observase en la existencia del código rural $^{57} \mathrm{y}$ en la preocupación de las autoridades por la seguridad del territorio, habida cuenta la escasa presencia policial y el aumento poco tranquilizador de los índices de criminalidad. El código refería que las autoridades locales no podían dictar reglamentos sobre vagancia y podían sólo limitarse a la observación de personas que pareciesen "sospechosas" por su falta de medios de vida. Por otra parte, no se prohibía llevar armas, lo cual se consideraba una práctica para ejercer una defensa legítima, habida cuenta la extensión de la violencia.

A pesar de que el Territorio no tiene a principios del siglo XX "masas ingobernables", que constituyen la base de la preocupación tanto de los funcionarios estatales como de la élite intelectual de las ciudades más importantes del país, no por ello se desiste de la vigilancia de los que se consideran peligrosos para el desarrollo pacífico de la comunidad pampeana. Están en la mira una multitud heterogénea, que pueden o no haber cometido un delito, pero que forman parte de la población en "estado peligroso", es decir,

56 El debate sobre la cuestión social implicó un avance de la medicalización sobre los sectores populares, para evitar el contagio social y la degeneración de la raza. Ver al respecto Armus, Diego: Mundo urbano y cultura popular. Ensayos de historia social argentina, Sudamericana, Buenos Aires, 1990, Barrán, J. P. et al.: Sectores populares y vida urbana, CLACSO, Buenos Aires, 1984 y Suriano, Juan, Cuestión social...

57 Se sancionó como Ley n. 3088 en 1898 . Se trató de disposiciones aplicables exclusivamente en los Territorios Nacionales. En relación con la represión, el Título II trataba el procedimiento que debia llevar a cabo la policía rural referidas al allanamiento, reuniones públicas, juego y embriaguez. 
que tiene riesgo de cometerlo ${ }^{58} \mathrm{El}$ argumento del daño potencial a la comunidad lleva a que los marginales, muchos de ellos alcohólicos, sean denunciados en los expedientes de Insania. ${ }^{59}$ Otro sector de riesgo para la criminología y medicina positivista lo constituye el grupo de inmigrantes, que en el caso del Territorio no implica una preocupación menor, habida cuenta el porcentaje de la población extranjera dentro del total. ${ }^{60}$

Por último, puede señalarse a las prostitutas y menores. En el primer caso, existió, en forma paralela a otras regiones de Argentina, un interés sobre todo municipal por regular esta actividad formalmente, para evitar no sólo la extensión de la sífilis sino también la disgregación familiar y social. En el segundo, se trató de una preocupación evidenciada por las mujeres de los sectores más altos de la sociedad pampeana, a partir de la labor desarrollada por la Sociedad de Beneficencia. ${ }^{61}$

Los dos casos testigo analizados ejemplifican las teorías criminológicas positivistas en la Pampa y definen en particular a los sectores de riesgo, acercando precisiones acerca de las expectativas de juristas y médicos sobre el comportamiento normal y de las conductas aceptadas para cada sexo y clase social. La caracterización de los criminales y locos permite entonces iniciar una conceptualización de la "cuestión social" en la Pampa, agregándolos en esta primera evaluación como sujetos sociales a los que obviamente es preciso estudiar en su complejidad histórica.

Por otra parte, al demarcar entre normales y anormales y dentro de éstos últimos a los enfermos y criminales, se hacen además otras adapta-

58 El "estado peligroso" como tal no fue efectivamente sancionado en la legislación penal, a pesar de los esfuerzos realizados por diferentes juristas y médicos, como se observa en la argumentación de Nerio Rojas, especialista en medicina legal (Rojas, Nerio: Medicina legal, Librería El Ateneo, Buenos Aires, 1953 (1936), págs. 437). Tal como señala Salvatore, Ricardo ("Sobre el surgimiento"), no fue necesario incluir dentro del código penal esta figura que implicaba directamente a los criminólogos positivistas, ya que de hecho existió en las prácticas jurídicas un acuerdo por prevenir el ejercicio del delito de acuerdo a la metodología científica y la teoría de la "defensa social".

59 Ver como ejemplos AHJ, Expediente 655, Luján, Juana, (1918), AHJ, Expediente 822, Neuman, Guillermo (1920) y AHJ, Expediente 591, Lacerre, Juan Pedro (1923), donde vecinos u oficiales denuncian los casos a la policía.

60 Entre 1910-1921, se sucedieron sobre todo en el Sudeste pampeano una serie de movimientos y huelgas de agricultores y arrendatarios que fueron severamente reprimidas, a partir de la Ley de Defensa Social. Muchos de los organizadores y participantes eran inmigrantes socialistas y anarquistas (Asquini, Norberto et al.: Conflictos sociales en La Pampa (1910-1921), FEB, Santa Rosa, 1999, Gutiérrez, Leandro y Ricardo González: "Pobreza marginal en Buenos Aires, 1880-1910", en: J. P. Barrán. et al.: Sectores populares y vida urbana, CLACSO, Buenos Aires, 1984, págs. 233-249.

61 Ver Di Liscia, María Herminia et al.: "Prostitutas. Registros y fotos", en: Villar, Daniel, et al., eds., Historia y Género. Seis estudios sobre la condición femenina, Biblos, Buenos Aires, 1999, págs. 11-32. 
ciones de acuerdo a la realidad local. La histeria, que como nosología había resultado confusa pero que en este momento estaba firmemente instalada como enfermedad femenina para los especialistas médicos, no calificó de acuerdo a la interpretación jurídica como argumento para señalar una acción realizada sin consciencia y determinar así la ininputabilidad criminal. ${ }^{62}$ De hecho, esta neurosis implicó una vinculación estrecha con la simulación y aunque se tratase de una somatización inconsciente, médicos y juristas enfatizaron esa relación que liga también al género. Por último, la evaluación médico-jurídica, que tuvo consecuencias diferenciales entre ambos sujetos, mujer y varón, implica el ejercicio de la autoridad estatal para imponer valores sociales que normaticen las relaciones de género de acuerdo a las expectativas burguesas.

62 En el Fuero Civil, de los 168 casos relevados por Insania sólo en uno de ellos se menciona la "manía histérica" como causa de enajenación mental. En el caso fue perito el médico José Oliver y juez Alfredo Torres. AHJ, Expediente 45, Austroky, Magdalena, Santa Rosa, 1916. 